\title{
Wound care in Sri Lanka: our patients deserve better care
}

\author{
A multidisciplinary approach and dedicated clinical care are prerequisites
}

Chronic ulcers are a major problem in health care worldwide [1-5]. Wound care is a much neglected field in Sri Lanka. Care of a wound, and advising and supervising the medical team to carry out the necessary measures in wound care, is a basic duty of a clinician. Wounds are an ideal opportunity to demonstrate the 'art and science of healing'. Patients with chronic wounds are often shunned by the family, employers and the society. Empathy and compassion should be essential attributes of the wound care team, in addition to a sound scientific knowledge on wound healing. A person with a chronic wound would be happy to see the wound heal. Even the care-giver derives much satisfaction to see a wound-free patient.

Much progress has been made in understanding the wound healing process in the last two decades and some of that knowledge has translated into practice by way of advanced dressings and genetically engineered bioproducts. No studies are available from Sri Lanka on the economic burden of chronic ulcers and their sequelae. It has been estimated that in the UK the total annual cost of treatment of leg ulcers is UK $£ 230-400$ million [6].

\section{Causes of chronic ulcers}

In Sri Lanka the common causes of chronic ulcers include, diabetic ulcers, neuropathic ulcers (e.g. leprosy), pressure ulcers, burns, venous ulcers and arterial ulcers [7]. In addition, there are non-healing ulcers such as pyoderma gangrenosum and Marjolin's ulcers.

The mechanisms currently adopted by doctors and the 'care' that the patients receive in the case of chronic ulcers, is certainly suboptimal in Sri Lanka [7]. Sometimes in busy wards, doctors and nurses delegate the duty of wound inspection and dressings to unqualified medical attendants. This is far from satisfactory.

Several factors have led to the inadequate care of patients with chronic ulcers. Poor emphasis on wound care by clinicians and health care managers, and lack of proper dressings and other facilities, trained wound care nurses, cohesive multidisciplinary approach (e.g. vascular surgeons, dermatologists, plastic surgeons, diabetologists, wound care nurses, pediatrists), and ignorance about the long term cost of improper wound management are some reasons. Recognition of curable causes of chronic ulcers (e.g. tuberculosis, amoebiasis, cutaneous melioidosis) and more sinister causes (e.g. squamous cell carcinoma, basal cell carcinoma, amelanotic melanoma) cannot be done by untrained personnel. Clinicians should evaluate chronic ulcers at least periodically.

Overuse of topical antibiotics on chronic ulcers is a common practice, especially at primary care level. This often complicates the healing process (e.g. development of resistant organisms, contact dermatitis, wound bed irritation). What is more relevant is to prepare the wound bed so that the natural healing mechanisms can take effect $[8,9]$. Severe pain is a distressing feature of certain types of ulcers. Pain management of chronic ulcers, especially at dressing changes, is another aspect which needs more attention [10].

The size of the ulcer or the area of the ulcer is not measured or recorded in most wards. At dressing changes this should be recorded. Some centres use simple methods of measurement, whereas some centres abroad use computerised methods [11]. Recording the status of the ulcer base, margins and the size should be emphasised in routine wound management.

Inadequate care of ulcers can have an immediate serious medical outcome or a great socio-economic impact. For example, as an immediate result, a diabetic patient may lose a limb through an emergency amputation or even die of septicaemia or ketoacidosis if a wound is not managed properly. Proper management of diabetes and diabetic ulcers would save lives as well as prevent amputations; and in the long run, save millions of rupees that would be spent on unnecessary wound care. As a long term sequel, any chronic wound has the potential to develop a squamous cell carcinoma (Marjolin's ulcer) which could lead to fatal secondary deposits if not detected and treated early. Even a non- 
malignant ulcer, if badly managed, may lead to fibrosis of the surrounding tissue and contractures, which will delay or prevent healing.

Loss of productivity by amputees as well as loss of man-hours, cost of surgery and hospitalisation have great implications on the person, family, society and the economy. Prevention of ulcers, especially in those more prone to such chronic ulcers (e.g. leprosy, diabetes), should also be a part of a good wound care strategy.

\section{Recent advances in wound care}

Many developments have taken place in the last two decades in understanding wound healing. Some of these have led to the development of a more advanced dressing material and genetically engineered biological material. Advanced hydrocolloid dressings, exudate absorbing dressings, calcium alginate dressings, bacteria trapping hydrofibre dressings, cadexomer iodine dressings, nanocrystalline silver dressings, collagenase ointment (enzymatic debriding agent), and growth factors enhancing wound healing are some examples $[2,3,6,8,12-$ 17]. Cultured epidermal grafts and artificial skin substitutes which provide a scaffold for the epithelial cells to grow, are other advances [18]. Use of vacuum pumps in large wounds with high levels of serous exudate have also proven useful in some types of ulcers. Hyperbaric oxygenation is another useful method of enhancing wound healing in ischaemic ulcers [19]. However, this is expensive as special airtight pressurizable chambers are needed for this form of therapy.

Even without sophisticated expensive dressings, proper wound bed preparation and conventional dressings alone would lead to wound healing in a large number of chronic wounds. Wound bed preparation involves a debridement phase, elimination of wound exudate and correction of the wound microenvironment [9].

\section{What can be done in the Sri Lankan setting?}

The clinicians should take greater interest and responsibility in wound management. They should examine ulcers and decide on the cause of non-healing ulcers, decide on the optimal type of dressings, how frequently the dressings should be changed, what measures to be taken to provide conducive conditions for wound healing (e.g. control of diabetes, varicose vein surgery, arterial surgery, correction of nutritional deficiencies), and refer for relevant investigations (e.g. Doppler studies, duplex scanning angiography, transcutaneous oxymetry) and appropriate surgical measures (e.g. skin grafts, vascular surgery). A focussed, multidisciplinary team approach would be in the best interest of the patient. Other than the clinicians involved, adequately trained wound care nurses could also play a vital role. More nurses should be trained in the art and science of wound healing, through workshops and other educational programs. As facilities for the care of wounds have to be available at medical institutions of all levels (primary, secondary and tertiary care), adapting to work with limited resources is also necessary. Preparation of 'guidelines on wound management' for clinicians in Sri Lanka should be undertaken by a multidisciplinary team of experts. The public should be educated through the media to avoid unhealthy practices which can lead to wound infection and poor healing. They should also be educated on prevention of potentially chronic ulcers, such as diabetic foot ulcers and trophic ulcers in other neuropathic conditions.

Scientific evaluation of traditional wound care practices, as well as the value of laboratory experiments on herbal products, cannot be underestimated. Economic advantages of finding efficient, safe, natural products would be enormous to a developing country. In Sri Lanka, it is known that some clinicians use unripe papaya and aloe vera in wound care when expensive hydrocolloid dressings are not available or affordable [20]. These practices have to be properly evaluated and documented before accepting the results as they are still anecdotal reports or uncontrolled studies. Ethically conducted, prospective, well-designed trials would be most welcome. The side-effects of such treatments should also be recorded.

Caring for wounds to alleviate suffering of the patients with chronic ulcers also gives an opportunity to have a greater and more rewarding doctor-patient relationship, moving away from commercialism and 'defensive medicine'. There should be a greater emphasis on wound care by health care services in Sri Lanka.

\section{Conclusions}

Patients with chronic ulcers need more dedicated care. The current status of wound care in Sri Lanka is very unsatisfactory. Modalities can be evolved, even with the limited resources available, to deliver better care for wounds. A collective approach by clinicians of relevant specialities, wound care nurses and health care managers would be essential to uplift the standard of wound care in Sri Lanka.

\section{References}

1. Ryan TJ The Management of Leg Ulcers. 2nd edn. Oxford: Oxford University Press, 1987.

2. Ryan S, Perrier L, Sibbald RG. Searching for evidencebased medicine in wound care: an introduction. Ostomy Wound Management 2003; 49: 67-75.

3. Choucair MM, Bello YM, Phillips TJ. Wound dressings. In: Fredberg IM, Eisen AZ, Wolff K, Austen KF, Goldsmith LA, Katz SI, eds. Fitzpatrick's Dermatology in General Medicine. 6th edn. New York: McGraw Hill, 2003: 2544-9.

4. Ong CK, Ryan TJ. Healthy Skin for All; A Multifaceted Approach. 1st edn. Oxford: International Foundation for Dermatology, 1998. 
5. Coleman DJ. Wounds, tissue repair and scars. In: Russel RCG, Williams NS, Bulstrode CJK, eds. Bailey and Love's Short Practice of Surgery. 23rd edn. London: Arnold, 2000: 29-39.

6. Sundsberg J, Meller R. A retrospective review of the use of cadexomer iodine in the treatment of chronic wounds. Wounds 1997; 9: 68-86.

7. Kumarasinghe SPW, Karunaweera ND, Ihalamulla IR. A study of cutaneous myiasis in Sri Lanka. International Journal of Dermatology 2000; 39: 689-94.

8. Falanga V. Occlusive wound dressings: why, when, which? Archives of Dermatology 1988; 124: 872-7.

9. Schultz GS, Sibbald RG, Falanga V, Ayello EA, Dowsett $\mathrm{C}$, et al. Wound bed preparation: a systematic approach to wound management. Wound Repair and Regeneration 2003; 11 (Suppl I): S1-S28.

10. Nemeth KA, Harrison MB, Graham ID, Burke S. Pain in pure and mixed aetiology venous leg ulcers: a three-phase point prevalence study. Journal of Wound Care 2003; 12: 336-40.

11. Kanthraj GR, Srinivas CR, Shenoi SD, Suresh B, Ravikumar BC, et al. Wound measurement by computeraided design (CAD): a practical approach for software utility. International Journal of Dermatology 1998; 37: 714-5.

12. Kannon GA. Moist wound healing with occlusive dressings: a clinical review. Dermatologic Surgery 1995; 21: 583-90.

13. Moffatt CJ, McCullagh L, O'Connor T, Doherty DC, Hourican C, et al. Randomized trial of four-layer and two- layer bandage systems in the management of chronic venous ulceration. Wound Repair and Regeneration 2003; 11: $166-71$.

14. Adam DJ, Naik J, Hartshorne T, Bello M, London NJ. The diagnosis and management of 689 chronic leg ulcers in a single-visit assessment clinic. European Journal of Vascular and Endovascular Surgery 2003; 25: 462-8.

15. Wisenbud D, Hunter H, Kessler L, Zulkowski K. Hydrogel wound dressings: where do we stand in 2003? Ostomy Wound Management 2003; 49: 52-7.

16. Bianchi L, Ginerbi A, Hagman JH, Francesconi F, Carboni I, et al. Local treatment of chronic cutaneous leg ulcers with recombinant human granulocyte-macrophage colony-stimulating factor. Journal of European Academy of Dermatology and Venereology 2002; 16: 595-8.

17. Miraftab M, Quao Q, Kennedy JF, Groocock MR, Anand SC. Advanced wound care materials: developing an alginate fibre containing branan ferulate. Journal of Wound Care 2002; 11: 353-6.

18. Hanft JR, Surprenant MS. Healing of chronic foot ulcers in diabetic patients treated with a human fibroblast-derived dermis. Journal of Foot and Ankle Surgery 2002; 41: 291-9.

19. Abidia A, Laden G, Kuhan G, Johnson BF, Wilkinson $\mathrm{AR}$, et al. The role of hyperbaric oxygen therapy in ischaemic diabetic lower extremity ulcers: a double-blind randomized-controlled trial. European Journal of Vascular and Endovascular Surgery 2003: 25: 513-8.

20. Wimalawansa SJ. Papaya in the treatment of chronic infected ulcers. Ceylon Medical Journal 1981; 26: 129-32.

SPW Kumarasinghe, Dermatologist, Colombo North Teaching Hospital, Ragama, Sri Lanka. Tel: +94 12806131 , e-mail: prasadkumarasinghe@yahoo.com (Competing interests: none declared).

\section{What's your price?}

About six months ago a woman representing a drug company rang me and said that she would take me to "the restaurant of my choice" if we would change our policy on economic evaluations and consider a paper that her company had sponsored. She stopped short of offering to go to bed with me, but I was surprised by her crassness. "Are you trying to bribe me?" I asked. "No," she answered brightly, "just being nice."

Richard Smith. Editor's choice. British Medical Journal 2003; 327: 298 